\title{
Comparison of Sea Surface Variation Derived from Global Navigation Satellite System (GNSS) and Co-tidal in Java Sea
}

\author{
Danar Guruh Pratomo ${ }^{1, *}$, Khomsin ${ }^{1}$, and Khariz Syaputra ${ }^{1}$ \\ ${ }^{1}$ Geomatics Engineering, Institut Teknologi Sepuluh Nopember, Surabaya, Indonesia
}

\begin{abstract}
Tide represents the vertical variation of sea surface. This parameter plays important rules in bathymetric survey. The conventional method to observe the sea surface variation is by using tide pole. Nowdays, a Global Navigation Satellite System (GNSS) can be used as a means to measure the variation of sea surface as it provides high accuracy coordinates. In this research, the vertical component of GNSS was utilized to analyze the variation of sea surface. The distance between tidal stations and the survey area can be a constrain to the depth reduction because its tidal zoning.The traditional tidal zoning is a discrete model. This can be minimalized using a co-tidal chart. In this research, the vertical variation of sea surface from GNSS and co-tidal chart approachs were examined and compared to the conventional method. The comparative analysis was performed with Root Mean Square Error (RMSE). The maximum and minimum RMSE during 3 days period between the GNSS and conventional approach are $0.246 \mathrm{~m}$ and $0.051 \mathrm{~m}$, respectively. Whereas, the maximum and minimum RMSE between the co-tidal chart model and the conventional approach at the same time are $0.286 \mathrm{~m}$ and $0.109 \mathrm{~m}$.
\end{abstract}

\section{Introductions}

Tide is a natural phenomenon of water surface's periodic rise and fall as the result of celestial objects' gravity, especially the moon and sun. Influence of other astronomical objects can be excepted since the distance and size are relatively smaller than the moon and sun. Tide on quasi-closed area like bay is affected by nonastronomical factors, such as coastal forms and basic topography [1].

Tidal observations are generally carried out on the beach or dock / harbor using tide pole or other tide gauge equipment. Tidal characteristics observed at the beach or dock / port are only valid for areas within a certain radius from the observation point. Outside of the area, as offshore, the tidal characteristics are usually determined indirectly by prediction using co-tidal charts.

Tidal observations are carried out with the aim to record vertical sea level movements that occur periodically. Results of tidal observations can be used as a correction to the depth surveyed. Sometimes, tidal observation conducted quite far from the survey location. So there's a possibility that the tide data is invalid for correction. This situation happened because the characteristics of the tides can differ from one region to another [2].

Global Positioning System (GPS) can be used to overcome tidal characteristics differences in different places. GPS can be used on a boat along with the sounding. Observations using GPS aims to position both horizontally and vertically with millimeters accuracy. To achieve high accuracy using GPS, differential kinematic methods can be used both real-time kinematic (RTK) and post-processed kinematic (PPK). In some cases, Differential GPS (DGPS) used [3].

This research was conducted with the aim to determine the differences found in sea level height results from tidal observation data using GPS and the results of co-tidal data. To find out the difference between these two data, this research must be done in the same place with relatively in the same time period. Knowing the differences in sea level height results from tidal observations using GPS and the results of co-tidal data on tide pole observation, conclusions can be drawn in which observational data has the smallest accuracy error.

\section{Methods}

\subsection{Location}

The location of this research took a case study of the Java Sea in the coordinates of $2^{\circ} 27^{\prime} 35,21^{\prime \prime}-8^{\circ} 23^{\prime} 0,26^{\prime \prime}$ LS dan $105^{\circ} 49^{\prime} 9,76^{\prime \prime}-119^{\circ} 41^{\prime} 44^{\prime \prime}$ BT. 


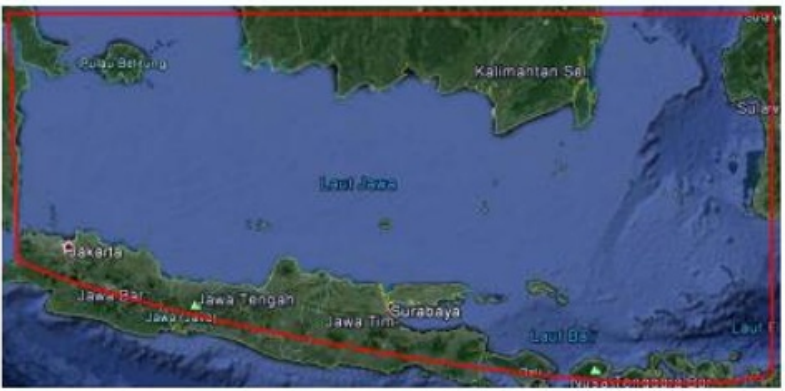

Fig. 1. Research Location

\subsection{Data and Tools}

Data used in this research are both primary and secondary data, specified as below:

a. GPS tide observation data using moving ship on Java Sea, April $26^{\text {th }}$ to April $28^{\text {th }}$ 2018.

b. Tide observation data using tide pole April $26^{\text {th }}$ to April $28^{\text {th }} 2018$.

c. Geoid model data (EGM2008).

d. Coastline data of Java Sea (GSHHG).

e. Observation data from 25 tidal stations on Java Sea waters February $1^{\text {st }}$ to March $1^{\text {st }}$, 2018.

As for equipments used in this research are software for data processing, such as:

a. RTKLIB for GPS data processing.

b. Alltrans EGM2008 Calculator 1.2 for EGM2008 data processing.

c. Matlab R2014a for tidal data processing.

d. PydroGIS 18.4 for tidal and co-tidal modelling.

e. ArcGIS 10.3 for layouting the data results.

\subsection{Data Processing}

Steps on data processing are explained as below:

a. GPS Tide Data Processing

GPS tide observation data used to obtain sea level. Sea level generated from this data is still refers to ellipsoid. Geoid EGM2008 model data then used to correct sea level which still refers to ellipsoid, becoming sea level refers to geoid (assumed its coincide with MSL).

b. Tide and Co-Tidal Modellling

Data from 25 tidal stations and coastline are used to make tidal models. Method for making the tide model is the triangulation interpolation method. Results of the tidal model are then exported to be processed into co-tidal and to obtain sea level height values that have MSL reference.

c. Comparative Analysis of GPS Tide Observation Data and Co-tidal toward Tide Pole Observation Data.

Tide pole observation data are used as comparative data on GPS and co-tidal sea level value. Analysis is done by comparing the accuracy level from the comparison of 2 sea level height values (GPS compared to tide pole and co-tidal compared to tide pole). Root Mean Square Error (RMSE) was calculated to test the accuracy level between these two

\section{Result}

\subsection{Result of GPS Tide Observations}

The results of GPS tide observations show GPS observation date and time, ellipsoid height, undulation, and orthometric height. The time of GPS observation varies for each day. This is due to the condition of a conditional measurement schedule. The average GPS observation time for each day is 5-6 hours with interval every 10 seconds.

Orthometric height is the final result of GPS observation which refers to geoid. Where, the height of the geoid is assumed to coincide with the mean sea level (MSL). The height is obtained by correcting the ellipsoid height value with undulation and the height value of the GPS antenna against sea level. Thus, the final value of orthometric height is the sea level that refers to geoid (coincides with MSL). The sea level height of the GPS observation results is shown in the GPS tide chart as in Figure 2, 3 and 4.

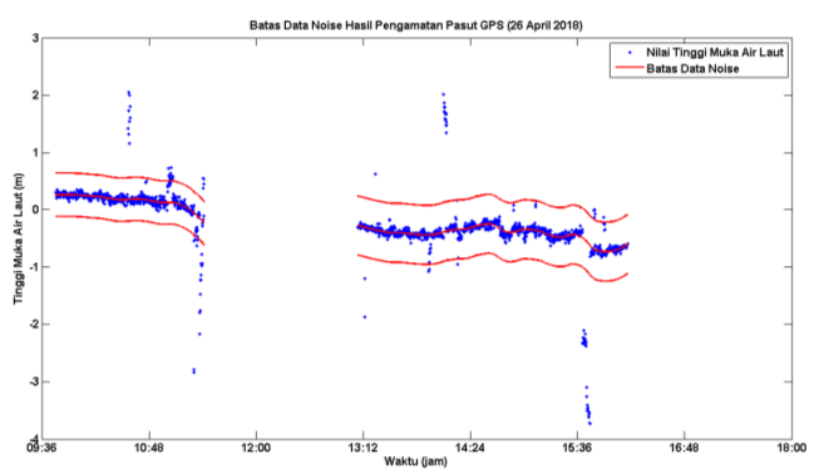

Fig. 2. Noise GPS Tide (26 April 2018)

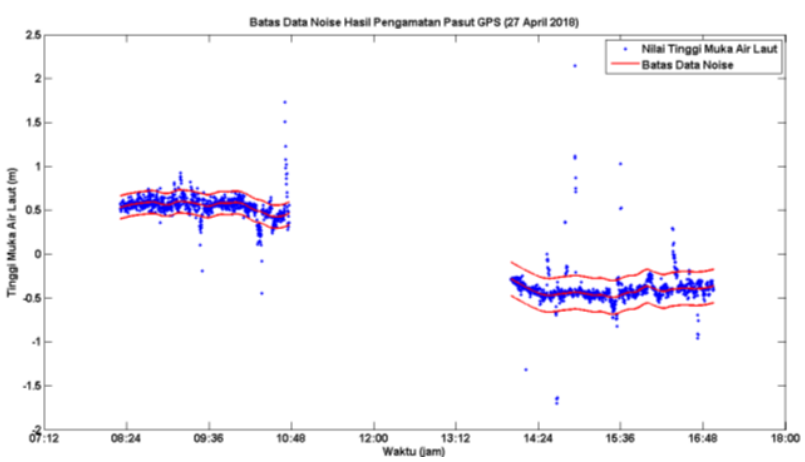

Fig. 3. Noise GPS Tide (27 April 2018) 


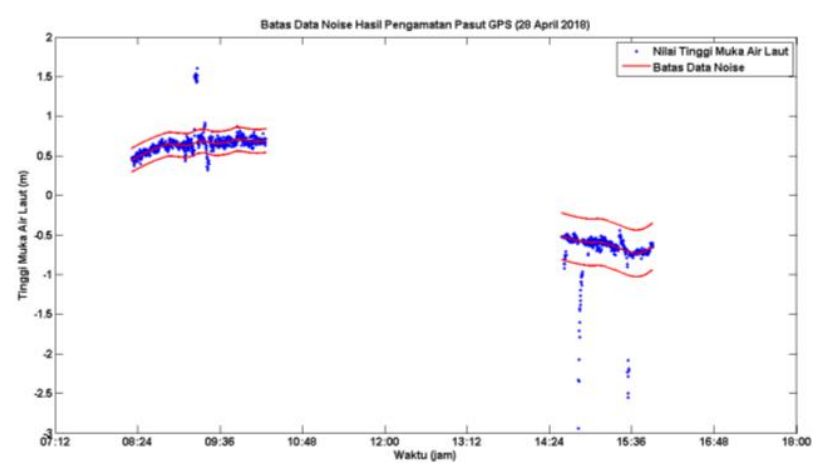

Fig. 4. Noise GPS Tide (28 April 2018)

Figure 2, 3 and 4 shows the graph of sea level on 26th, 27th and 28th April 2018. The sea level is already referring to geoid (coinciding with MSL) in meter unit. The graph shows there is noise data that is outside the upper and lower limits of the data. Data that is outside the upper and lower limit will need to be cleaned to obtain a smooth GPS observation graph. The results of cleaning and smoothing of GPS sea level data are shown in the graph in Figure 5, 6 and 7.

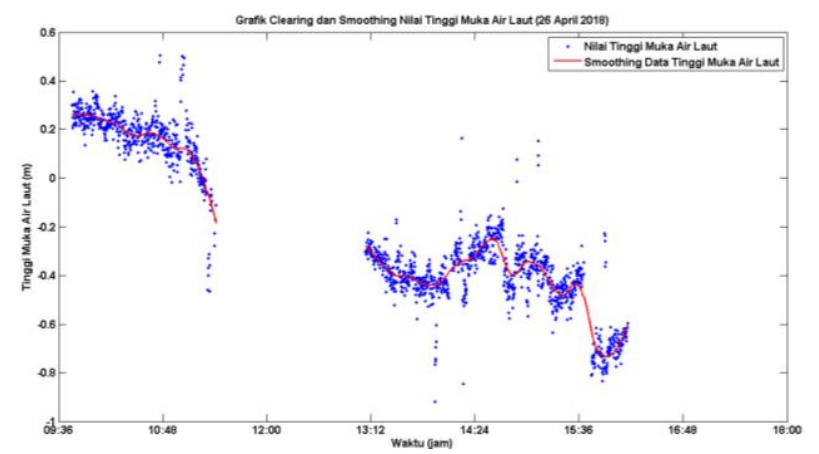

Fig. 5. Smoothing GPS Tide (26 April 2018)

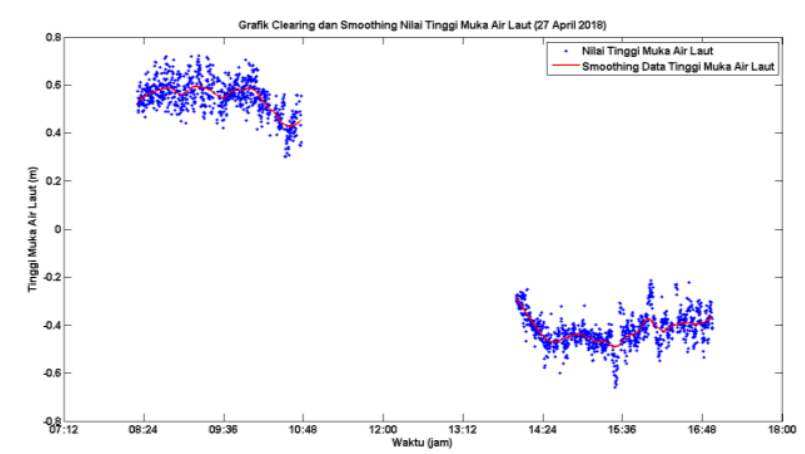

Fig. 6. Smoothing GPS Tide (27 April 2018)

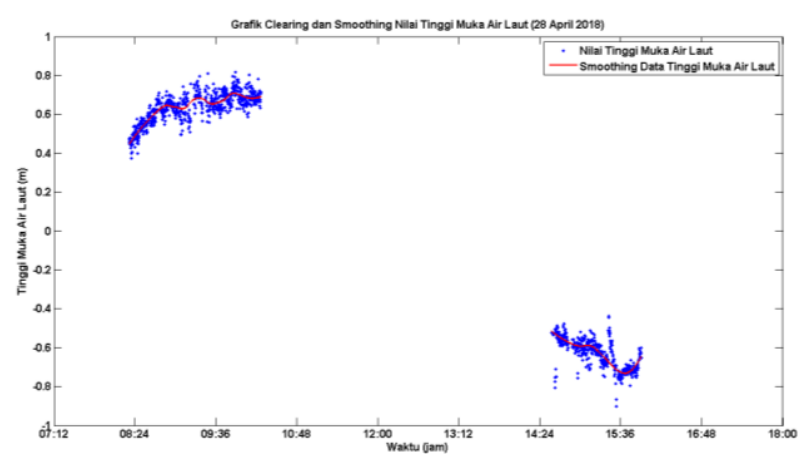

Fig. 7. Smoothing GPS Tide (28 April 2018)

Figure 5, 6 and 7 show the smoothing observations of GPS tides on April 26th, 27th and 28th 2018. The smoothing results are obtained from the results of GPS tide data that have been cleared from noise. The method used to perform data noise clearing and data smoothing is the moving average filtering method. The process is carried out to minimize the effects of vessel / boat movements that cause data noise. The data of GPS tide observations of this smoothing result will be compared to the co-tidal data and observation of tide pole.

\subsection{Result of Tide and Co-tidal Modeling}

The results of the tide model that is processed using Pydro 18.4 are in the form of contours of the amplitude and phase values of each constant (M2, S2, N2, K1, and O1). The values of each amplitude and phase are obtained by using the least square method on the Matlab $\mathrm{R} 2014 \mathrm{a}$. The data used is the observation data of 25 tidal stations.

The amplitude that generated at each constant indicate the values variation at 25 tidal stations. The largest amplitude for the $\mathrm{K} 1$ constant is at the Bangka tidal station with a value of 0.811 meters. The largest amplitude for M2 constant is at Ketapang station with a value of 0.477 meters. The largest amplitude for the N2 constant is at the Ketapang tidal station with a value of 0.094 meters. The largest amplitude for the $\mathrm{O} 1$ constant is at the Bangka tidal station with a value of 0.521 meters. The amplitude for S2 constant is at Kotabaru tidal station with a value of 0.497 meters.

The resulting phase value shows the direction and magnitude of the constant wave propagation in degrees. The phase in each harmonic constant is the tidal phase against equilibrium tides in Greenwich. Variations in the value and direction of propagation that show differences at each tidal location against the tidal force. To see the differences more clearly, variations in values and directions in the amplitude and phase in each tidal station are processed into a mesh (domain model) of the tidal model which is then exported to co-tidal charts.

Mesh of tide model is obtained from the interpolation process of tidal observation data, tidal constituent and phase data, and vertical datum data as a reference for sea level height. The interpolation method used is the triangulation method. Figure 8 shows the results of the tide mesh model. 


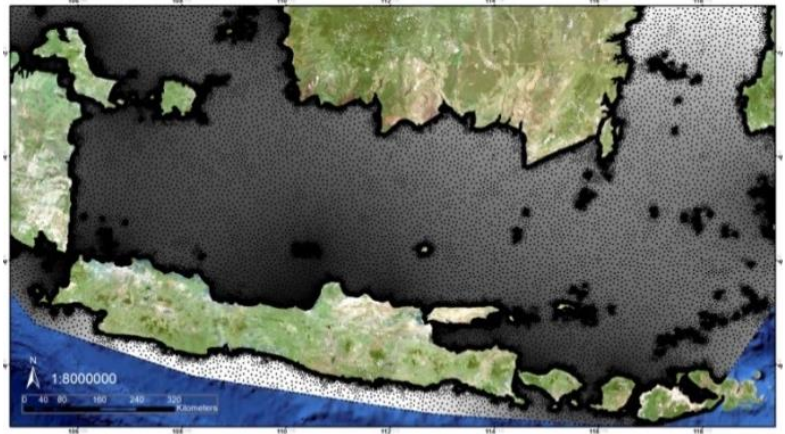

Fig. 8. Result of Tide Mesh Model

This triangulation method works by making triangles that do not intersect. Where, for each interconnected triangles have different weights. The weighting value generated in the interpolation process is represented by the midpoints of the triangles at each coordinate of the interpolation result.

Besides being able to export the amplitude and phase contour values which are then processed into co-tidal charts, the tide model which is processed from the mesh making process (domain model) from the observation data of 25 tidal stations can also be exported to determine the sea level height value. The resulting sea level can be exported at certain coordinates as needed. The vertical datum that is used can also be set according to the required needs. In Figure 9, 10 and 11 are shown the graphical pattern of co-tidal sea level height.

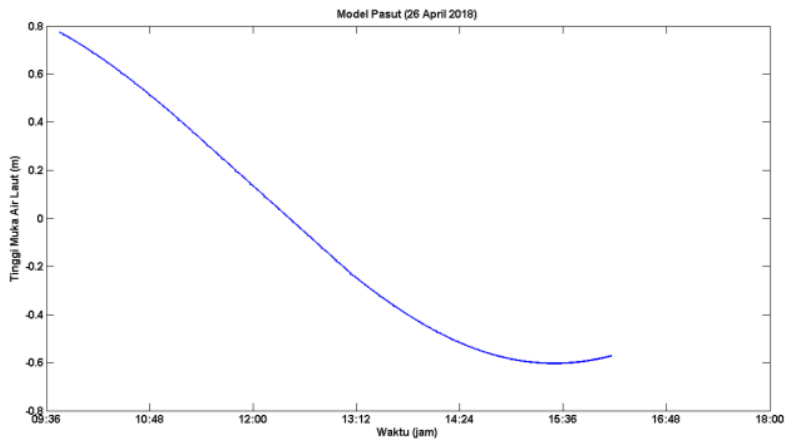

Fig. 9. Sea Level Height from Co-tidal (26 April 2018)

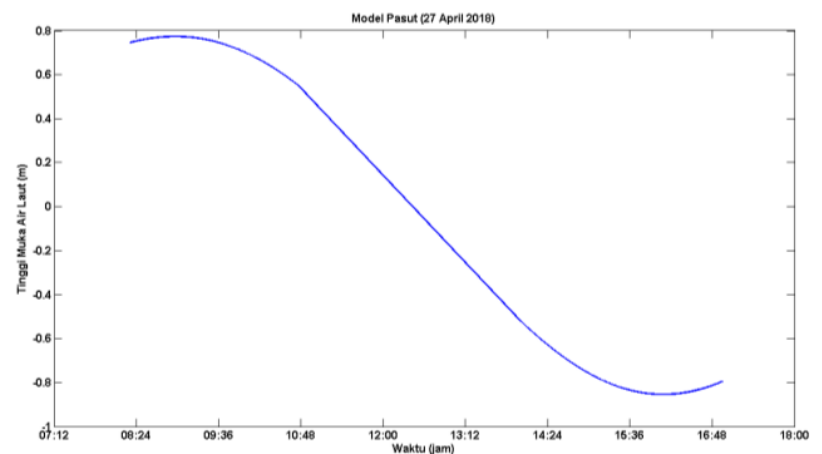

Fig. 10. Sea Level Height from Co-tidal (27 April 2018)

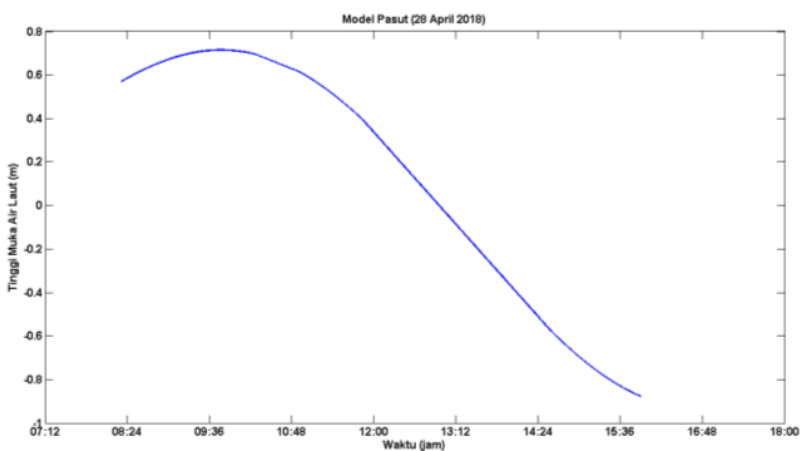

Fig. 11. Sea Level Height from Co-tidal (28 April 2018)

Figure 9, 10 and 11 show the chart pattern of co-tidal water level on the 26th, 27th and 28th April 2018. The graph shown has a pattern that is relatively the same as the sea level height chart of the GPS smoothing results shown in the previous section. Comparison of graph patterns between sea level highs of GPS smoothing results and co-tidal to sea level height observations of tide pole will be explained in the next section.

\subsection{Comparison of GPS Tide and Co-tidal to Observation of Tide Pole}

In this research, a comparison of sea surface variation data from the results of 2 observations of sea level height was carried out by observing tide pole. Whereas, the sea level height values of these observations are assumed to be correct data. The first, is the comparison of the sea level height of the results of GPS observations on sea level height values observed by tide pole. The second, is the comparison of the value of co-tidal sea level (tidal model) to the sea level height observed by tide pole.

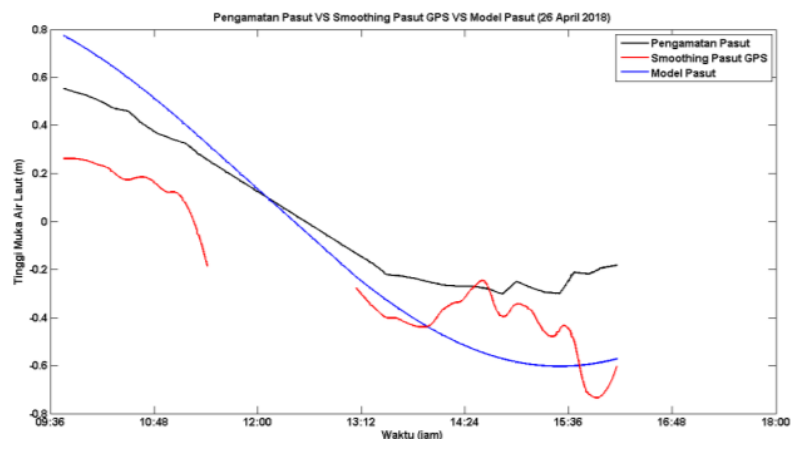

Fig. 12. Comparison of Sea Level Height (26 April 2018)

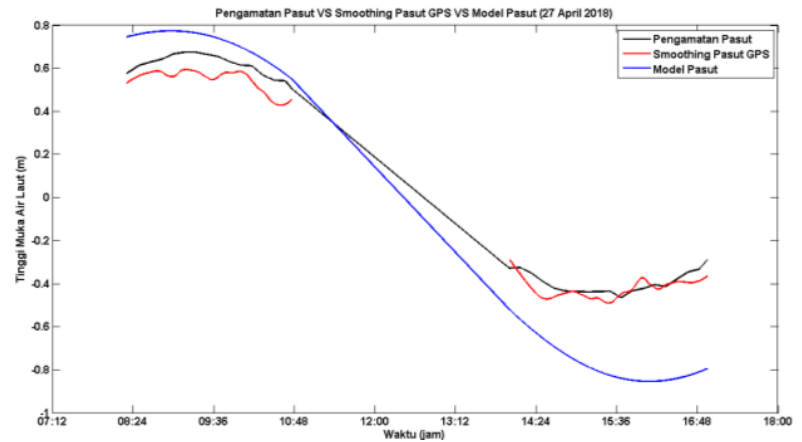

Fig. 13. Comparison of Sea Level Height (27 April 2018) 


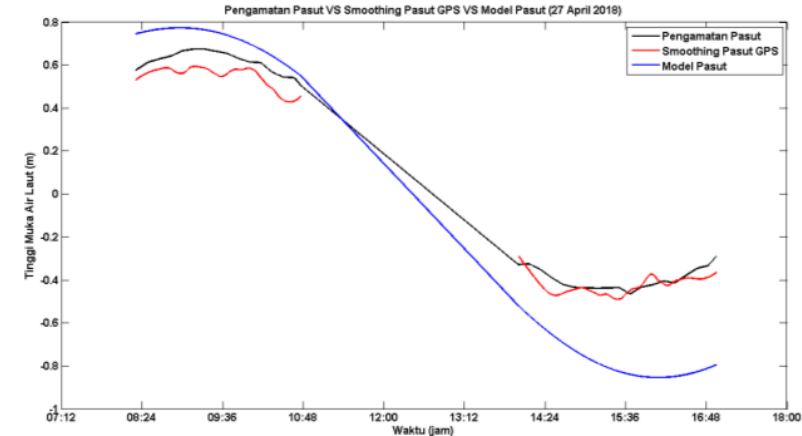

Fig. 14. Comparison of Sea Level Height (28 April 2018)

Figure 12, 13 and 14 show a comparison graph of sea level height on April 26th, 27th and 28th 2018. The sea level height graph from GPS observations is shown with a red graph. Graph of sea level co-tidal results (tidal model) is shown with a blue graph. Charts of sea level height observed by tide pole are shown with a black graph. Overall, the chart pattern of the three sea level height values produced is relatively the same but has a difference in sea level height. In this research, analysis of sea level height which was carried out from GPS, cotidal, and tide pole is by looking for sea level height values that are closest to sea level height values observed by tide pole which are considered correct data.

The analysis carried out is by calculating the level of accuracy on the value of the sea level of GPS results and cotidal results on sea level as a result of observations of tide pole. Accuracy test is done by calculating the RMSE (Root Mean Square Error) value at each observation time (26, 27, and 28 April 2018). RMSE calculations can be done using the following formula [4].

$$
R M S E=\sqrt{\frac{\sum_{i=1}^{n}\left(y_{i}-\hat{y}_{i}\right)^{2}}{n}}
$$

Where $\sum_{i=1}^{n}\left(y_{i}-\hat{y}_{i}\right)^{2}$ is the sum of the squares of the size minus the value that is considered true, and $n$ is the length of the data. From these calculations, the RMSE values are shown in Table 1 below.

Table 1. RMSE Values.

\begin{tabular}{|c|c|c|}
\hline Date & Comparison & RMSE \\
\hline \multirow{2}{*}{$26 / 4 / 2018$} & Tide Pole - GPS Tide & 0,246 \\
\cline { 2 - 3 } & Tide Pole - Co-tidal & 0,237 \\
\hline \multirow{2}{*}{$27 / 4 / 2018$} & Tide Pole - GPS Tide & 0,061 \\
\cline { 2 - 3 } & Tide Pole - Co-tidal & 0,286 \\
\hline \multirow{2}{*}{$28 / 4 / 2018$} & Tide Pole - GPS Tide & 0,051 \\
\cline { 2 - 3 } & Tide Pole - Co-tidal & 0,109 \\
\hline
\end{tabular}

In the comparison of sea level height values from tide pole and GPS tidal results, the largest RMSE value was on April 26th 2018 with a value of 0.246 meters. Meanwhile, on the next 2 days, on 27th and 28th April 2018, the resulting RMSE value was smaller with a value of 0.061 and 0.051 meters. The difference between the height of the sea level of the tide pole and the results of the GPS tide does not always provide a solution at the centimeter $(\mathrm{cm})$ level. There are times, the difference in the value of the sea level generated will reach the level of decimeters (dm) up to meters (m). This can occur due to several factors as follows [5]:

a. Error on base station height measurement

b. Error in measuring the height of the rover antenna

c. Error in the separation model.

Meanwhile, in the comparison of sea level height values from tide pole and co-tidal results, the largest RMSE value was on April 27, 2018 with a value of 0.286 meters. Meanwhile, on April 26 and 28 the resulting RMSE values were 0.237 and 0.109 meters. From the comparison of sea level height values, both between the results of the tide pole with GPS and between the results of the tide pole with co-tidal it can be seen that on April 27 and 282018 the average error value on the sea level of GPS results is smaller than cotidal average error results. It can be interpreted that the value of the sea level of the GPS results is closer to the sea level height of the tide pole.

\section{Conclusion}

The sea level height value generated from GPS observation data is referenced to the ellipsoid which is then corrected so that it refers to the geoid (assumed to coincide with MSL). Meanwhile, sea level height results from co-tidal and observation of tide pole refer to the mean sea level (MSL). The sea level height results from GPS observation data and the results of co-tidal have a relatively similar pattern to sea level height results from observations of tide pole at each observation time (26th, 27th, and 28th April 2018). Based on the resulting graph, the closest pattern is on the third day on 28th April 2018.

Comparison of sea level height of tide pole and GPS tides, the RMSE values obtained on April 26th was 0.246 meters, April 27th was 0.061 meters, and on April 28th was 0.051 meters. Whereas, in the comparison of sea level height of tide pole and co-tidal results, the RMSE value on April 26th was 0.237 meters, April 27th was 0.286 meters, and on April 28th the resulting RMSE value was 0.109 meters. From the comparison of sea level height, both between the results of the tide pole with GPS and between the results of the tide pole with co-tidal it can be seen that on 27th and 28th April 2018 the average error value on the sea level of GPS results is smaller than co-tidal average error results. It can be interpreted that the value of the sea level height of the GPS is closer to the sea level height of the tide pole.

\section{References}

1. R. H. Stewart. Intoductioan to Physical Oceanography. Am. J. Phys. (2008)

2. S. Haryono, Narni. Karakteristik Pasang Surut di Pulau Jawa. Forum Tek, 28 (2004) 
3. H. Z. Abidin. Penentuan Posisi dengan GPS dan Aplikasinya. (2007)

4. C. D. Ghilani, P. R. Wolf. Adjusment Computations: Spatial Data Analysis. (2011)

5. D. J. Mills, Dodd. Ellipsoidally Refenced Surveying for Hydrography. (2014)

6. S. R. Deloach. GPS Tide: A Project to Determine Tidal Datums with The Global Positioning System. (1995)

7. M. Cisternelli, Gill. Implementation of TCARI into NOS Hydrographic Survey Operation. (2014) 